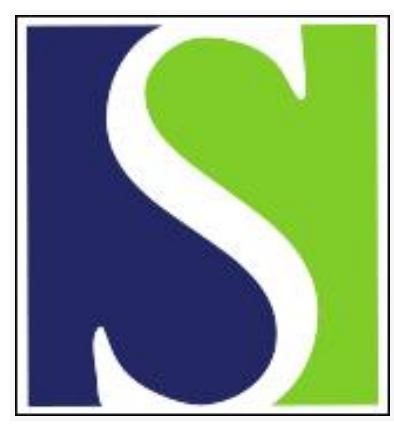

Scand J Work Environ Health 1989;15(6):383-386

https://doi.org/10.5271/sjweh.1835

Issue date: Dec 1989

Respiratory cancer mortality among workers employed in thermoelectric power plants.

by Forastiere F, Pupp N, Magliola E, Valesini S, Tidei F, Perucci CA

Affiliation: Epidemiologic Unit, Latium Regional Health Authority, Rome, Italy.

This article in PubMed: www.ncbi.nlm.nih.gov/pubmed/2617254

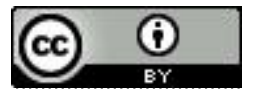




\title{
Respiratory cancer mortality among workers employed in thermoelectric power plants
}

\author{
by Francesco Forastiere, MD, ${ }^{1}$ Nicoletta Pupp, MD, ${ }^{2}$ Elisabetta Magliola, BA, ${ }^{1}$ \\ Serena Valesini, BA, ${ }^{1}$ Felice Tidei, BA, ${ }^{2}$ Carlo A Perucci, MD ${ }^{1}$
}

\begin{abstract}
FORASTIERE F, PUPP N, MAGLIOLA E, VALESINI S, TIDEI F, PERUCCI CA. Respiratory cancer mortality among workers employed in thermoelectric power plants. Scand $J$ Work Environ Health 1989;15:383-386. A historical cohort study of 406 workers was undertaken to evaluate the possible health hazards of employment in traditional electric power plants with particular regard to cancer mortality. The total mortality was below that expected [observed 40, standardized mortality ratio (SMR) 87] on the basis of national rates. Cancer mortality was slightly increased (SMR 112), mainly because of an excess of respiratory cancer (observed 9, SMR 171, $90 \%$ CI 89-299). Lung cancer deaths were higher than expected among those less than 60 years of age and among those with a duration of exposure and a latency period since first employment of over 10 years (observed 7, SMR 184). Furthermore, the increase was more pronounced among maintenance workers and workers in general services. Previous data indicated that there had been past exposure to some known respiratory carcinogens (ie, asbestos, polycyclic aromatic hydrocarbons). This study suggests that a possible lung cancer risk from traditional electricity generating plants should be considered and further studied.
\end{abstract}

Key terms: asbestos, electrical workers, lung cancer.

In discussions on the future energy supply concern is often expressed about possible health hazards in nuclear power plants, whereas less attention is paid to the health implications of conventional thermoelectric energy production. However, in a critical cross-comparison of the risks of the two types of production systems, Cohen \& Pritchard (1) had to conclude that no data were available on occupational cancer risks in oilor coal-burning power stations. More recently an increased risk of cancer among workers in conventional thermoelectric power plants has been reported (2). In particular, past exposure to several known or suspected carcinogens (asbestos, polycyclic aromatic hydrocarbons, hydrazine, chromium, nickel, and beryllium) was considered a putative factor in the observed increase in total cancer mortality. Furthermore, there is another recent hypothesis which also seems to call for additional studies of power plant workers, namely, the possibility that electromagnetic fields, as present in power plants (as well as elsewhere), could have some impact on human health (3). Since the operating staff of a power station (both conventional and nuclear) is limited in size, it is difficult to produce large studies of these workers, but the health hazards may nevertheless be evaluated from the aggregated data of several studies.

In view of these circumstances the present historical cohort study was undertaken to clarify further the

\footnotetext{
' Epidemiologic Unit, Latium Regional Health Authority, Rome, Italy.

2 Local Health Unit RM/21, Civitavecchia, Italy.
}

Reprint requests to: Dr F Forastiere, Regional Epidemiologic Unit, Via Santa Costanza 53, 1-00198 Rome, Italy. possible health hazards connected with employment in two traditional thermoelectric power plants, with particular regard to cancer mortality.

\section{Subjects and methods}

Two plants located in Civitavecchia (Latium, Italy) were included in the study. The first started operation in 1953 as a coal-fired plant producing a power of 70 $\mathrm{MW}$; in 1959, the power was raised to $220 \mathrm{MW}$. In 1962 the fuel was changed to oil and, in 1969, the power was again increased, to $460 \mathrm{MW}$. The second plant has been operating with oil since 1964 and produces a power of $200 \mathrm{MW}$; in the period 1969-1973 three new generating units (320 MW each) were added.

Historical measurements of airborne dust are not available, even though a possible exposure to asbestos, especially during maintenance work, is likely to have occurred (4). In 1982, a special hazard control program was set up to avoid air contamination from asbestos fibers during insulating operations, ie, the local exhaust ventilation was increased, wetting was initiated, and control of waste through the use of plastic sheeting was begun. Despite this program, in a survey conducted in 1985 during a routine maintenance outage, a range of 1.8-9.5 asbestos fibers (chrysotile asbestos) $/ \mathrm{cm}^{3}$ was found in four samples collected inside the protected area and 3.5 fibers $/ \mathrm{cm}^{3}$ in a sample collected in the surrounding atmosphere. It could be hypothesized that past exposure to asbestos had been even higher and more widespread in the general work environment, given the former absence of asbestos control measures. 
Personnel records relative to all workers active on 1 January 1968 or those who were subsequently employed up to 31 December 1970 were made available by the company. A retrieval of all subjects ever employed was impossible because of changes in the recording system. From these records we obtained the

Table 1. Distribution of the subjects according to vital status (as of 31 December 1986), age when hired, and length of employment.

\begin{tabular}{lrr}
\hline & Number & $\%$ \\
\cline { 2 - 3 } & & \\
Vital status & 360 & 88.7 \\
Known to be alive & 40 & 9.9 \\
Know to be deceased & 6 & 1.5 \\
Vital status unknown & 406 & 100 \\
Total & & \\
Age when hired (years) & 180 & 44.3 \\
$16-25$ & 119 & 29.3 \\
$26-35$ & 84 & 20.7 \\
$36-45$ & 23 & 5.7 \\
$46-55$ & & 4.9 \\
Length of employment (years) & 20 & 57.1 \\
$1-10$ & 232 & 37.9 \\
$11-20$ & 154 & \\
$>20$ & & \\
\hline
\end{tabular}

Table 2. Distribution of person-years at risk of dying by age group.

\begin{tabular}{lrr}
\hline Age (years) & Person-years & $\%$ \\
\hline $15-24$ & 241 & 3.3 \\
$25-34$ & 1818 & 25.1 \\
$35-44$ & 2344 & 32.3 \\
$45-54$ & 1546 & 21.3 \\
$55-64$ & 999 & 13.8 \\
$65-74$ & 296 & 4.1 \\
$75-84$ & 6 & 0.1 \\
\hline Total & 7251 & 100 \\
\hline
\end{tabular}

Table 3. Cause specific mortality among the workers at the two thermoelectric power plants. $(\mathrm{O}=$ number of observed deaths, $E=$ expected number of deaths, SMR = standardized mortality ratio, $90 \% \mathrm{Cl}=90 \%$ confidence interval)

\begin{tabular}{|c|c|c|c|c|}
\hline Cause of deatha & 0 & $\mathrm{E}$ & $\mathrm{SMR}^{\mathrm{b}}$ & $90 \% \mathrm{Cl}$ \\
\hline All malignant neoplasms $(140-209)$ & 16 & 14.31 & 112 & $70-170$ \\
\hline $\begin{array}{l}\text { Digestive organs }(150-159) \\
\text { Respiratory system }(161-163) \\
\text { Larynx (161) } \\
\text { Trachea, bronchus and lung (162) } \\
\text { Urinary and genital organs (180-189) } \\
\text { Lymphatic and hemopoietic } \\
\text { tissues }(200-209)\end{array}$ & $\begin{array}{l}2 \\
9 \\
1 \\
8 \\
2\end{array}$ & $\begin{array}{l}4.37 \\
5.26 \\
0.59 \\
4.50 \\
1.15\end{array}$ & $\begin{array}{r}46 \\
171 \\
\cdot \\
178 \\
174\end{array}$ & $\begin{array}{r}8-144 \\
89-299 \\
88-321 \\
31-547 \\
\end{array}$ \\
\hline Circulatory diseases $(390-450)$ & 17 & 15.67 & 108 & $69-163$ \\
\hline Respiratory diseases $(460-519)$ & - & 2.65 & $\cdot$ & $\cdot$ \\
\hline $\begin{array}{l}\text { Diseases of the digestive } \\
\text { system }(520-577)\end{array}$ & 2 & 4.79 & 42 & $7-131$ \\
\hline $\begin{array}{l}\text { Diseases of the genitourinary } \\
\text { system }(580-629)\end{array}$ & - & 0.58 & . & $\cdot$ \\
\hline III-defined diseases $(790-796)$ & 2 & 0.41 & 488 & $87-1536$ \\
\hline Accidents (800-999) & 3 & 4.97 & 60 & $16-156$ \\
\hline All causes $(000-999)$ & 40 & 45.95 & 87 & $66-113$ \\
\hline
\end{tabular}

a The codes of the International Classification of Diseases (eight revision) are shown in parentheses.

$b$ The SMR values were not computed for categories with only one death. following information for the employees: name, birth date, place of residence, dates of first and last employment at the facilities, and job titles. For each subject the vital status for the period 1 January $1968-31$ December 1986 was ascertained either through the company records of workers still active or through the registry office of the last municipality of residence. Causes of death, retrieved from the registry office of the place where death occurred, were coded according to the eighth revision of the International Classification of Diseases.

A modified life-table analysis program was used to calculate the person-years for at risk of dying (5). Each subject was considered from 1 January 1968, or from the subsequent date of first employment, through the end of the study date (31 December 1986) or the date of death. Workers lost to follow-up were considered alive at the end of the follow-up. National causespecific death rates for men, stratified by age (five-year classes) and calendar period (five-year classes), for the period 1969-1983 were multiplied by the corresponding person-years of the cohort. Mortality figures for the period 1969-1973 were also used for the year 1968, and the 1979-1983 national death rates were applied to the remaining years, 1984-1986.

The standardized mortality ratio (SMR) was calculated as the ratio between the observed and expected deaths multiplied by 100 . The $90 \%$ confidence interval $(90 \% \mathrm{CI})$ of the SMR, based on the assumption of a Poisson distribution of the observed cases, was calculated with the use of Fisher exact limits. They correspond to confidence intervals computed with a onetailed P-value of 0.05 .

\section{Results}

A total of 406 workers were ever employed at the plants at some point between 1968 and 1970 . Table 1 presents the frequency distribution of the study cohort by vital status at the end of the follow-up period, age at first employment, and duration of employment. Only a small proportion of the subjects was untraceable for vital status; the majority of workers were under 35 years of age when hired. Short-term employees with a total of less than one year of employment have not been included in the study group, while $37.9 \%$ of the subjects had worked for more than 20 years. The person-years of observation were 7251; table 2 shows their distribution by the age of the employees.

Fewer than the expected number of deaths occurred for all causes (observed 40, expected 45.95, SMR 87, $90 \% \mathrm{CI} 66-113$ ) mainly because of a "healthy worker effect" among those with a short latency time from first employment (latency $\leq 10$ years: observed 4, expected 8.50 , SMR 47 ; latency $>10$ years: observed 36 , expected 37.45, SMR 96). For most causes the observed mortality was not different from the expected (table $3)$. The total cancer mortality was slightly increased 
(observed 16, expected 14.31, SMR 112), mainly because of an excess in respiratory cancer (observed 9, expected 5.26, SMR 171), although the confidence intervals of the SMR (90\% CI 89-299) included the null value.

Eight lung cancer deaths were observed, while 4.50 were expected on the basis of national mortality rates (SMR 178, $90 \%$ CI 88-321). The SMR for lung cancer was raised among those less than 60 years of age (observed 6, expected 2.43, SMR 247, 90 \% CI 108487), while no increase was found among the older subjects (observed 2, expected 2.07, SMR 97). Table 4 presents the relationship between lung cancer, duration of employment, and time since first employment. Only a few deaths are present in each of these categories, and a clear trend is not evident. Nevertheless, the SMR values appear to be increased when both duration of exposure and latency period from first employment exceed 10 years. Workers with a latency time of 10 to 20 years or greater than 20 years had SMR values of 200 and 152, respectively. Furthermore, the worker classified as having a short exposure period and latency had been working for an additional eight years as an electrician (on contracted work) in one plant.

Finally, the analysis of lung cancer according to job title, as obtained from the company records, showed that increased risk occurred mainly among maintenance workers (mechanics, insulators, welders, electricians) (observed 4, expected 1.85, SMR 216, $90 \%$ CI 74-495) and among those employed in general services (including cleaners) (observed 2, expected 0.74 , SMR 270, $90 \%$ CI 48-851), whereas no cases were found among the technicians (expected 0.30) and two cases were recorded among the general operators (expected 1.58, SMR 127, $90 \%$ CI 22-398).

\section{Discussion}

While a total cancer mortality similar to that expected from the general population was observed in the study group, some increase in lung cancer was found. Even though chance alone could explain the observed increase, it is worth noting that there are some factors that seem to suggest a causal role of the workplace. The increase among younger ages, for instance, when certification of death should be of high quality, is characteristic and similar to what has been described for some well-known lung carcinogens. Furthermore, the increased risk remained when a longer duration of exposure and latency period from first employment was considered. Interpretation of the findings from the analysis by job titles is difficult because only a few lung cancer deaths occurred in each category. On the other hand, the excess found among maintenance workers and cleaners makes the association with the workplace more plausible because such workers have presumably been heavily exposed to airborne pollutants, especially asbestos fibers. One of the lung cancer cases, in fact, had been working as a full-time insulator. With regard to the whole cohort, however, the number of workers directly involved in handling asbestos was low (around 10), since all the insulating operations had gradually been transferred to outside contractors.

The increase found with regard to lung cancer is consistent with that determined in two other epidemiologic studies conducted on workers employed in thermoelectric plants in northern Italy $(6,7)$. Five and six lung cancer cases were observed in Turbigo (6) and near Venice (7), respectively, while 2.83 and 4.39 , respectively, were expected on the basis of general population mortality rates. The confidence intervals of the SMR values included the null value, but both studies had a low power to detect a statistically significant association.

With regard to the internal validity of the study some points should be considered. First, smoking represents a potential confounder in this study, but complete information on this aspect was not available. On the other hand, we examined the smoking habits of 235 active workers at the plants as reported during periodic health examinations in the years 1986 and 1987. Reference figures for smoking for the general population were available from a national interview survey carried out in $1983(8)$; in a comparison of the estimates of the prevalence of smoking, an age adjustment was applied with the age distribution of the working population at the plants as the standard. The prevalence of nonsmokers at the plants $(32.3 \%)$ was similar to that of the general population $(34.8 \%)$; current smokers in the sample were less represented in com-

Table 4. Lung cancer cases by time since first employment and duration of employment at the plants. $(O=$ observed, $E=$ expected, SMR = standard mortality ratio)

\begin{tabular}{|c|c|c|c|c|c|c|c|c|c|c|c|c|}
\hline \multirow{3}{*}{$\begin{array}{l}\text { Duration of } \\
\text { employment } \\
\text { (years) }\end{array}$} & \multicolumn{12}{|c|}{ Time since first employment (years) } \\
\hline & \multicolumn{3}{|c|}{$1-10$} & \multicolumn{3}{|c|}{$10-20$} & \multicolumn{3}{|c|}{$>20$} & \multicolumn{3}{|c|}{ Total } \\
\hline & 0 & $E$ & $\mathrm{SMR}^{\mathrm{a}}$ & $\mathrm{O}$ & $E$ & SMR $^{\mathrm{a}}$ & 0 & $\mathrm{E}$ & $\mathrm{SMR}^{\mathrm{a}}$ & 0 & $E$ & $\mathrm{SMR}^{2}$ \\
\hline $1-20$ & 1 & 0.52 & . & - & 0.16 & . & - & 0.01 & . & 1 & 0.69 & . \\
\hline $10-20$ & - & 0 & . & 4 & 1.84 & 217 & 1 & 0.72 & . & 5 & 2.56 & 195 \\
\hline$>20$ & - & 0 & - & - & 0 & . & 2 & 1.25 & 160 & 2 & 1.25 & 160 \\
\hline Total & 1 & 0.52 & . & 4 & 2.00 & 200 & 3 & 1.98 & 152 & 8 & 4.50 & 178 \\
\hline
\end{tabular}

a The SMR values were not computed for categories with only one death. 
parison to the national estimate (46.4 versus $55.0 \%$ ), while the proportion of ex-smokers was higher (21.3 versus $10.2 \%$ ). The "smoking adjusted" expected number of lung cancer deaths, calculated according to the indirect method suggested by Axelson \& Steenland (9), was 4.27 , ie, somewhat lower than the crude estimate of 4.50. Therefore, a positive confounding effect from smoking is unlikely to have occurred in this study.

Second, the Latium region, where the plants are located, has mean annual certification rates for lung cancer deaths among men that are very similar to those of Italy as a whole. During the period 1969-1978, a directly standardized lung cancer death rate of 56.5 (per 100000 inhabitants) was observed for Latium, whereas 53.9 was the rate recorded for Italy. Therefore, the use of national reference rates instead of the Latium regional data could not explain the increased risk of lung cancer.

Third, due to the incompleteness of the records of subjects ever employed, the cohort composition was mainly of a cross-sectional type ( 350 of the study members were active on 1 January 1968), and only a small proportion of the workers $(13.8 \%)$ were hired during the three subsequent years. Therefore, the mortality experience of those retired before 1968 was missing. Since the original populations could have been subjected to different degrees of selection pressures, a possible selection bias could have been introduced. Considering, however, that the elapsed time from the start of plant operation to the beginning of observation was not long, the extent of such a bias should be trivial.

Finally, it is worth noting that the power of this study to detect an increased risk of lung cancer was low. Given an alpha of 0.1 (two-sided) and an SMR of 150 and 200 , the probability of detecting a significantly increased risk (1-beta) was only 0.27 and 0.57 , respectively.

In conclusion, workers at two thermoelectric power plants seemed to incur some additional risk of lung cancer, but it is difficult to establish the precise etiologic factor. Asbestos appears to be the most plausible agent, even if other substances present in the work environment and during maintenance work could have acted alone or in combination with asbestos. In evalu- ating the potential health hazards associated with different electricity production systems, a possible cancer risk from traditional electricity generating plants should be considered and further studied.

\section{Acknowledgments}

We wish to thank Professor Axelson for his support and comments during the design of the study and his review of an earlier draft of the paper.

The work has been partially funded by the Italian National Research Council (CNR "Progetto Finalizzato Energetica 2," contract no 84.02888.59).

\section{References}

1. Cohen AV, Pritchard DK. Comparative risks of electricity production systems: a critical review of the literature. London: Her Majesty's Stationery Office, 1980. (Health Safety Executive, research paper 11.)

2. Cammarrano G, Crosignani P, Berrino F, Berra G. Cancer mortality among workers in a thermoelectric power plant. Scand J Work Environ Health 1984;10:259-61.

3. Coleman M, Beral V. A review of epidemiological studies of the health effects of living near or working with electricity generation and transmission equipment. Int $\mathrm{J}$ Epidemiol 1988;17:1-13.

4. Hirsch A, Di Menza L, Carre A, et al. Asbestos risk among full-time workers in an electricity generating power station. Ann NY Acad Sci 1979;330:137-45.

5. Waxweiler RJ, Beaumont JJ, Henry JA. A modified life table analysis system for cohort studies. J Occup Med $1983 ; 25: 115-24$

6. Camarrano G, Crosignani P, Berrino F, Berra G. Additional follow-up of cancer mortality among workers in a thermoelectric power plant [Letter to the editor]. Scand J Work Environ Health 1986; 12:631-2.

7. Petrelli G, Menniti-Ippolito F, Taroni F, Raschetti R, Magarotto G. A retrospective cohort mortality study of workers of two thermoelectric power plants: fourteen-year follow-up results. Eur J Epidemiol 1989;5:87-9

8. Istat. Indagine statistica sulle condizioni di salute della popolazione e sul ricorso ai servizi sanitari (Novembre 1983). Rome: Istituto Centrale di Statistica, 1986. (Note e relazioni $\mathrm{n}$ 1.)

9. Axelson $O$, Steenland $K$. Indirect methods of assessing the effects of tobacco use in occupational studies. Am $\mathrm{J}$ Ind Med 1988;13:105-18.

Received for publication: 26 January 1989 